\title{
Assessment of pesticides residues in fish (Tilapia guineensis) in the Couffo River in Djidja (Benin).
}

\author{
Firmin H. Aïkpo ${ }^{1,2}$, Lucien Agbandji ${ }^{1}$, Miriac Dimitri S. Ahouanse ${ }^{2}$, Luc Koumolou ${ }^{1}$, S.
} Christophe Houssou ${ }^{2}$, A. Patrick Edorh ${ }^{1}$

\author{
${ }^{1}$ Research Laboratory in Biochemistry and Environmental Toxicology (LaRBiTE),University of Abomey-Calavi (UAC), 03 \\ PO.BOX 0994, Cotonou, Benin. \\ ${ }^{2}$ Laboratory Pierre Pagney "Climate, Water, Ecosystem and Development" (LACEEDE), University of Abomey-Calavi \\ (UAC), PO BOX 922,Cotonou, Benin.
}

\begin{abstract}
In Benin, the main cash crop is the cotton of which the level of production is largely insufficient to satisfy the national and international market. The main food crops (corn, cassava, yam, bean, rice, etc.) permit to cover the food needed globally, but remain again extensively on this side of the potentialities offered by the ecological conditions of the country. In the process to increase the agricultural production, the herbicides, insecticides and the fertilizers are used now in higher quantity that in the past. The aim of this work was to assess the level of contamination of fish (Tilapia guineensis) in the Couffo River in Djidja (Benin) by the pesticides. Nine (09) samples of fish (Tilapia guineensis) have been collected in nine (09) points along the Couffo River. The analysis of these fish has been done by gas chromatography after extraction and purification. In fish, the detected concentrations in average ranged between $0.123 \mu \mathrm{g} / \mathrm{kg}$ and $0.191 \mu \mathrm{g} / \mathrm{kg}$ for the glyphosate, from 0.095 to $0.128 \mu \mathrm{g} / \mathrm{kg}$ for the profenofos, between 0.112 and $0.125 \mu \mathrm{g} / \mathrm{kg}$ for the acetamiprid and 0.127 and 0.139 $\mu \mathrm{g} / \mathrm{kg}$. To assess the risk to public health, pesticides intake by fish consumption was estimated and compared with Estimated Daily Intake (EDI) values reported by the Codex Alimentarius. This comparison showed that fish consumption does not pose a risk for public health.
\end{abstract}

Keywords-Pesticides-Djidja-cotton-fish-River.

\section{INTRODUCTION}

In Benin, the main cash crop is the cotton of which the level of production is largely insufficient to satisfy the national and international market. The main food crops (corn, cassava, yam, bean, rice, etc.) permit to cover the food needed globally, but remain again extensively on this side of the potentialities offered by the ecological conditions of the country (MAEP, 2008). Reduction of the proliferation of pest and increase in food production, has made pesticides application in agriculture inevitable (Akoto et al., 2013). Pesticides are now included in our modern life and are used to protect agricultural land, stored grain, flower gardens as well as to eradicate the past transmitting dangerous infectious diseases (Harsimran and Harsh, 2014). Ideally, the applied of pesticides which should only be toxic to the target organisms, should be biodegradable and eco-friendly to some extent (Rosell et al., 2008). Unfortunately, this is hardly the case as most of the pesticides are effects. The presence of the pesticides in waters is a major concern because they are a serious threat in the biologic communities including human beings. There are different ways by which pesticides can get into water such as accidental spillage, industrial effluent, surface run off and transport from pesticides treated soils, washing of spray equipments after spray operation, drift into bridges, lakes streams and river water area spray to control waterinhibiting pests (Carter and Heather, 1995 ; Singh and Mandal, 2013). Pesticides generally move from fields to various water storages by run off or in drainage done by rain or irrigation (Larson et al., 2010). A lot of researches have been carried out to show the impact of pesticides on decline in fish population (Scholz et al., 2012). Fish are often used as indicators of such biological impacts of pollutants as they respond to low concentrations of toxic substance (Ayas et al., 2007). Aquatic organisms from the Kiti River and vegetable plants commonly consumed by the local people in the township of Djidja (Benin) were contaminated by metabolites of DDT (Pazou, 2014). The analysis of the concentration of organochlorines in fishes captured in the dam at Kpassa (Benin) show a relatively higher concentration (Fofana, 2012). The aim of this work was to assess the level of contamination of fish (Tilapia guineensis) in the Couffo River in Djidja (Benin) by the pesticides.

\section{MATERIALS AND METHODS}

\section{2-1- STUDY AREA}

The geographic scope of this work was the township of Djidja, the largest of the nine (09) townships of Zou department. Located between $7^{\circ} 10^{\prime}$ and $7^{\circ} 40^{\prime}$ north 
latitude, $1^{\circ} 40^{\prime}$ and $2^{\circ} 10^{\prime}$ west longitude, this township covers $41.66 \%$ of the total area of the department. With a total area of $2184 \mathrm{~km}^{2}$, it has a sub-equatorial climate next to Sudan Guinea in the northern parts (Akomagni, 2006).This township has a variety of soil (ferrallitic, ferruginous, vertisols, hydromorphic) and floodplains. The township is $145 \mathrm{~km}^{2}$ watered by Rivers from which Zou and Couffo are the most important (SDS, 2004). The vegetation is composed of several formations (palm groves, wooded savannah, savannah, forest islands, galleries). The township of Djidja is located in the cotton area in the Centre of Benin. This area is dominated by cereals, tubers and vegetables. The population is $80 \%$ invested in agricultural activities.

\section{2-2- METHODS}

\section{2-2-1- Sampling of fish}

Nine (09) samples of fish (Tilapia guineensis) have been captured in three (3) different points along the Couffo River from $15^{\text {th }}$ to $19^{\text {th }}$ of March 2014. The collection of fish has been done under the surveillance of the Laboratory IRGIB-AFRICA that started the previous processing and ensures adequate packaging and conservation before sending the samples to the Laboratory. These fish have been chosen because they are most consumed by the local population.

\section{2-2-2- Preparation of the samples}

The preparation of the samples of fish has been done by the Laboratory IRGIB - AFRICA and took in consideration the pesticides as the glyphosate, the profenofos, the acetamiprid and the cypermethrin. These pesticides have been selected on the basis of their frequency use. A Solution standard stock (75 to 550 $\mathrm{pg} / \mathrm{ml}$ ) has been prepared by exact weighing. It has been dissolved in the acetone and has been stocked in a freezer to $-30^{\circ} \mathrm{C}$ without exhibition to light. This Solution stock standard of work $(5 \mu \mathrm{g} / \mathrm{ml})$ has been prepared by dilution suitable of cyclohexane and has been stored inside a refrigerator $\left(4^{\circ} \mathrm{C}\right)$ and rinsed with the hexane.

\section{2-2-3- Extraction by gas chromatography}

The procedure of extraction of the samples by gas chromatography is the following. A sample of $200 \mathrm{~g}$ of fish has been chopped and has been homogenized. A quantity of $15 \mathrm{~g}$ of the aliquot has been put in one glass and mixed with $50 \mathrm{ml}$ of dichloromethane (DCM) and stake in a centrifuge during 2 minutes. Of the sulphate of the anhydrous sodium $(50 \mathrm{~g})$ has been added to the

Dietary exposure $=$ mixture that has been put again in a centrifuge during one minute. The mixture has been rested during 2 minutes then filtered through a Büchner funnel of $9 \mathrm{~cm}$ and has been filtered again through a paper (Wattman) and of the anhydrous sodium sulphate. The solvents evaporated to dry in a rotary evaporator $\left(35^{\circ} \mathrm{C}-40^{\circ} \mathrm{C}\right)$. The dried residual has been taken and one added $5 \mathrm{ml}$ of cyclohexane there. In a phial of $2 \mathrm{ml}$ containing $50 \mu \mathrm{l}$ of solution internal stallion of $20 \mathrm{mg} / \mathrm{l}, 1 \mathrm{ml}$ of this solution has been added to reach the final of $2 \mathrm{ml}$ in volume of cyclohexane.

\section{2-2-4- Pesticides Analysis}

The determination of pesticides was performed by gas chromatography. A mass spectrometer with high resolution DSQII Thermo was used. The chromatograph used for analysis is a gas chromatograph equipped with a Thermo Scientific split / splitless injector and a temperature controlled GC-MS interface. A smuggler AS 3000 sample was used. A quantity of $10 \mu \mathrm{l}$ of aliquots was injected into the gas chromatograph (GC) operating using a syringe with an injection rate of $20 \mu$ l. The initial injection temperature at the nozzle was maintained at $70^{\circ} \mathrm{C}$ for 5 minutes, and increased and maintained for 10 minutes at $310^{\circ} \mathrm{C}$ and at $100^{\circ} \mathrm{C} /$ minute. The initial temperature at the oven was maintained at $70^{\circ} \mathrm{C}$ during 4 minutes, then increased to $150^{\circ} \mathrm{C}$ at $50^{\circ} \mathrm{C} /$ minute, then to $235^{\circ} \mathrm{C}$ with $3^{\circ} \mathrm{C} /$ minute at last maintained for 3 minutes at $300^{\circ} \mathrm{C}$ with $50{ }^{\circ} \mathrm{C} /$ minute. It has been operating the mass spectrometer and the vacuum pump to achieve a different level of "Vacuum" stable injection. The transfer line temperatures, the flow of gas (helium) were settled. The analysis was done with a multiplier filament delay of 5 minutes to prevent the shock ionization filament level.

\section{2-2-5- Dietary exposure assessment: method}

Dietary exposure assessment combines food consumption data and the concentration of the food additive in food. The resulting dietary exposure estimate may then be compared with the Acceptable Daily Intake (ADI) for the food additive, if available, as part of the risk characterization.

Three elements must be taken account in assessing the dietary exposure to a food additive: (1) the concentration of the food additive in food; (2) the amount of food consumed; and (3) the average body weight of the population $(\mathrm{kg})$. The general equation for dietary exposure according to Codex Alimentarius (2014) is:

Body weight $(\mathrm{kg})$ 
The Acceptable Daily Intake (ADI) is the amount of a food additive, expressed as $\mathrm{mg} / \mathrm{kg}$ body weight, that can be ingested daily over a lifetime without incurring any appreciable health risk.

\section{2-2-6- Estimated Daily Intake: method}

The Estimated daily Intake (EDI) of a food additive is the amount of an additive injected by the average consumer of the food based on a) the actual use of the additive by industry, or b) if the food additive is used according to Good Manufacturing Practice (GMP), an approximation as close as possible to the actual uses levels.

Not having statistical official on the middle daily consumption of fish per person in this township, an assessment of the quantity of fish consumed per day per person has been done on the basis of the data of an investigation led by 30 households in the 3 villages. the middle quantity of fish consumed per day and for a middleweight of $60 \mathrm{~kg}$ is valued to $150 \mathrm{~g}$. the maximal injection "adjusted" of pesticide residues per day and per person is calculated while taking in account the cooking that affects the level of pesticide residues in food of table (WHO, 1997).

The daily injection estimated of residue of pesticides (EDI) has been calculated according to the formula of WHO (1997):

EDI fish $\left(\mu \mathrm{g} \cdot \mathrm{kg}^{-1}\right.$ body weight per day $)=\mathrm{NR}\left(\mu \mathrm{g} \cdot \mathrm{kg}^{-1}\right) \mathrm{x}$ QAI ( $\mu$ g.kg ${ }^{-1}$ body weight per day).
EDI = Estimated Daily Intake.

$\mathrm{NR}=$ Level of pesticide Residue in the ingested fish. $\mathrm{QAI}=$ Quantity of fish Ingested.

The EDI has been calculated for the samples 1 of Zakan Kossossa, 2 of Fonkpodji and 1 of Aklinmè. These samples present most elevated middle concentrations in pesticides.

All data was analyzed by comparing results obtained for different concentrations of pesticides. An unpaired t- test was performed after verification of the homogeneity of the variance of the data. Results were represented as mean \pm SD and statistical significance was judged at $\mathrm{p}<0.05$.

\section{RESULTS}

The results of the analysis of the pesticides for fish collected are mentioned in Tables 1, 2 and 3 as follow.

The samples of fish collected in the village of Zakan Kossossa (Table 1) present some concentrations in relatively elevated pesticides. The glyphosate has been detected to middle concentrations that vary between 0.162 and $0.185 \mu \mathrm{g} / \mathrm{kg}$. The profenofos has been recovered to middle concentrations that range between 0.118 and 0.125 $\mu \mathrm{g} / \mathrm{kg}$. The acétamipride has been found to middle contents varying between 0.112 and $0.117 \mu \mathrm{g} / \mathrm{kg}$. The cypermethrin is disclosed to middle concentrations ranging between 0.129 and $0.139 \mu \mathrm{g} / \mathrm{kg}$. These results show that the middle concentrations in glyphosate in fish are higher than those of the other pesticides identified.

With:

Table.1: Concentrations of pesticides in fish (Zakan Kossossa site).

\begin{tabular}{ccccc}
\hline Sf & Glyphosate $(\mu \mathrm{g} / \mathrm{kg})$ & Profenofos $(\mu \mathrm{g} / \mathrm{kg})$ & $\begin{array}{c}\text { Acetamiprid } \\
(\mu \mathrm{g} / \mathrm{kg})\end{array}$ & $\begin{array}{c}\text { Cypermethrin } \\
(\mu \mathrm{g} / \mathrm{kg})\end{array}$ \\
\hline Sf 1 & 0.185 & 0.123 & 0.112 & 0.131 \\
Sf 2 & 0.169 & 0.118 & 0.117 & 0.139 \\
Sf 3 & 0.162 & 0.125 & 0.116 & 0.129 \\
ISD & \pm 0.172 & \pm 0.121 & \pm 0.113 & \pm 0.132 \\
CV & $09.75 \%$ & $02.95 \%$ & $02.26 \%$ & $05.03 \%$ \\
\hline
\end{tabular}

Sf = sample of fish; SD = Standard Deviation; CV = Coefficient of Variation

The samples collected in the village of Fonkpodji (Table 2) present some concentrations in variable pesticides. The glyphosate has been detected to middle concentrations that vary between 0.123 and $0.191 \mu \mathrm{g} / \mathrm{kg}$. The profenofos has been disclosed to middle concentrations that vary between 0.095 and $0.120 \mu \mathrm{g} / \mathrm{kg}$. The acetamiprid has been found to middle concentrations varying between 0.114 and $0.125 \mu \mathrm{g} / \mathrm{kg}$. The cypermethrin is identified to middle concentrations that vary between 0.128 and $0.132 \mu \mathrm{g} / \mathrm{kg}$. The middle concentrations in glyphosate discovered in these samples are also higher than those of the other pesticides recovered.

Table.2 : Concentrations of pesticides in fish (Fonkpodji site).

\begin{tabular}{ccccc}
\hline Sf & Glyphosate $(\mu \mathrm{g} / \mathrm{kg})$ & Profenofos $(\mu \mathrm{g} / \mathrm{kg})$ & $\begin{array}{c}\text { Acetamiprid } \\
(\mu \mathrm{g} / \mathrm{kg})\end{array}$ & $\begin{array}{c}\text { Cypermethrin } \\
(\mu \mathrm{g} / \mathrm{kg})\end{array}$ \\
\hline Sf 1 & 0.157 & 0.117 & 0.114 & 0.132 \\
Sf 2 & 0.191 & 0.120 & 0.125 & 0.130
\end{tabular}




\begin{tabular}{ccccc}
\hline Sf 3 & 0.123 & 0.095 & 0.114 & 0.128 \\
ISD & \pm 0.157 & \pm 0.109 & \pm 0.120 & \pm 0.13 \\
CV & $21.65 \%$ & $12.36 \%$ & $05.47 \%$ & $01.53 \%$ \\
\hline
\end{tabular}

$\mathrm{Sf}=$ sample of fish; $\mathrm{SD}=$ Standard Deviation; $\mathrm{CV}=$ Coefficient of Variation

In the samples of fish captured in Aklinmè (Table 3) the middle concentrations in pesticides are variable. The glyphosate has been identified to middle concentrations varying between 0.145 and $0.190 \mu \mathrm{g} / \mathrm{kg}$. The profenofos has been found to middle concentrations that vary between 0.113 and $0.128 \mu \mathrm{g} / \mathrm{kg}$. The acetamiprid has been detected to middle concentrations that vary between 0.117 and $0.121 \mu \mathrm{g} / \mathrm{kg}$. The cypermethrin has been disclosed to middle concentrations varying between 0.127 and 0.138 $\mu \mathrm{g} / \mathrm{kg}$.

The middle concentrations in glyphosate are higher than those of the other pesticides detected.

Table.3 : Concentrations of pesticides in fish (Aklinmè site).

\begin{tabular}{ccccc}
\hline Sf & Glyphosate $(\mu \mathrm{g} / \mathrm{kg})$ & Profenofos $(\mu \mathrm{g} / \mathrm{kg})$ & Acetamiprid $(\mu \mathrm{gg} / \mathrm{kg})$ & $\begin{array}{c}\text { Cypermethrin } \\
(\mu \mathrm{g} / \mathrm{kg})\end{array}$ \\
\hline Sf 1 & 0.190 & 0.126 & 0.117 & 0.138 \\
Sf 2 & 0.171 & 0.128 & 0.120 & 0.133 \\
Sf 3 & 0.145 & 0.113 & 0.121 & 0.127 \\
ISD & \pm 0.168 & \pm 0.121 & \pm 0.118 & \pm 0.131 \\
CV & $00.38 \%$ & $00.12 \%$ & $01.76 \%$ & $04.16 \%$ \\
\hline
\end{tabular}

$\mathrm{Sf}=$ sample of fish; $\mathrm{SD}=$ Standard Deviation; $\mathrm{CV}=$ Coefficient of Variation

The analysis of variance show there is a significant difference $(\mathrm{p}<0.05$ for the site of Zakan Kossossa; $\mathrm{p}<0.05$ for the site of Fonkpodji and $\mathrm{p}<0.05$ for Aklinmè site).

It is noticed from the Table 4 that the values of Estimated Daily Intake (EDI) are very lower to those fixed by the Codex Alimentarius. It is also noted how the consumption of these fish contaminated by these pesticides contributes to the consumer's Acceptable Daily Intake (ADI). The rate of contribution varies from 0.00 to $0.2 \%$ for the sample 1 of Zakan Kossossa, of 0.01 to $0.34 \%$ for the sample 2 of Fonkpodji and 0.00 to $0.4 \%$ for the sample 1 of Aklinmè.

The contribution of the glyphosate, the profenofos, the acetamiprid and the cypermethrin to the ADI of the consumer of these fish not reached $1 \%$. It is therefore low.

Table.4: Comparison of EDI with ADI $(150 \mathrm{~g})$.

\begin{tabular}{|c|c|c|c|c|c|c|c|c|c|c|}
\hline \multirow[b]{2}{*}{ Pesticides } & \multirow{2}{*}{$\begin{array}{c}\text { ADI } \\
(\mu \mathrm{g} / \mathrm{w} / \mathrm{d})\end{array}$} & & \multicolumn{8}{|c|}{ Concentrations of pesticides in fish $(\mu \mathrm{g} / \mathrm{kg})$} \\
\hline & & Sf $1(Z)$ & $\begin{array}{l}\text { EDI } \\
(\mu \mathrm{g} / \mathrm{w} / \mathrm{d})\end{array}$ & $\begin{array}{c}\% \\
\text { ADI }\end{array}$ & Sf $2(\mathrm{~F})$ & $\begin{array}{c}\text { EDI } \\
(\mu \mathrm{g} / w / d)\end{array}$ & $\begin{array}{c}\% \\
\mathrm{ADI}\end{array}$ & $\begin{array}{l}\text { Sf } 1 \\
\text { (A) }\end{array}$ & $\begin{array}{c}\text { EDI } \\
(\mu \mathrm{g} / w / d \\
)\end{array}$ & $\% \mathrm{ADI}$ \\
\hline Glyphosate & $300^{1}$ & 0,185 & 0,02 & 0,00 & 0,191 & 1,02 & 0,34 & 0,190 & 0,02 & 0,00 \\
\hline Profenofos & $100^{1}$ & 0,123 & 0,01 & 0,01 & 0,120 & 0,01 & 0,01 & 0,126 & 0,01 & 0,01 \\
\hline Acetamiprid & $70^{1}$ & 0,112 & 0,01 & 0,01 & 0,125 & 0,01 & 0,01 & 0,117 & 0,01 & 0,01 \\
\hline Cypermethrin & $50^{1}$ & 0,131 & 0,01 & 0,02 & 0,130 & 0,01 & 0,02 & 0,138 & 0,02 & 0,04 \\
\hline
\end{tabular}

${ }^{1}$ Codex Alimentarius. ADI: Acceptable Daily Intake. EDI: Estimated Daily Intake

Sf 1 (Z): Sample of fish 1 (Zakan Kossossa). Sf 2 (F): Sample of fish 2 (Fonkpodji). Sf 3 (A): Sample of fish 3 (Aklinmè).

\section{DISCUSSION}

The results of fish analysis show positive results of average concentrations of research pesticides. The measurement results of Tables 1, 2 and 3 show that all samples have average concentrations of glyphosate and higher level of cypermethrin. The most contaminated fish levels by the two pesticides are in this order the areas of Aklinmè, of Kossossa and of Fonkpodji. The average concentrations in profenofos and in acetamiprid in the three areas fish are relatively low compared to glyphosate and cypermethrin. The levels of most of the pesticides in fish are lowered in comparaison with Codex Alimentarius (2014) standard (normes). The risk of the consumption of these fish is limited in the event other sources of exhibition don't exist. However the pesticides residues found mean that the intensive pollution from these four pesticides will contribute to fishery pollution. Fish provide food source for other animals such as sea birds 
and marine mammals and thus fish form an integral part of the marine food web (Harsimram and Harsh, 2014). Pesticides have been directly linked to causing fish species are found to be affected by "plant protection products" (PPP) in Europe (Ibrahim et al., 2013). Pesticides used near aquaculture operations may also contaminate fish (FDA, 2001). The persistent pesticides (organochlorine pesticides and polychlorinated biphenyls) have already been found in the major Artic Ocean food webs (Hargrave et al., 1992). It was reported that such level of pesticides in fish could harm the fish consumers (Komar, 2011). Simultaneous exposure of trematode parasite (Telogaster opisthorchis), fresh water fish (Galaxias anmalus) and snails to high glyphosate concentrations significantly reduced their survival and development. Within $24 \mathrm{hrs}$ of exposure to higher glyphosate concentrations, $100 \%$ mortality of individuals was found (Kelly et al., 2010). The impact of pesticides within an aquatic environment is influenced by their water solubility and uptake ability within an organism (Pereira et al., 2010). Pesticides in natural water within the acceptable concentration range can still have harmful effects. Köck-Schulmeyer et al. (2012) found that even if the pesticides levels found in Llobregat River basin of Spain were within the European Union Environmental Quality Standards, they still accounted for a low to high ecotoxicological risk for aquatic organisms, especially algae and macro-invertebrates.

\section{CONCLUSION}

This study shows some degree of concentration in fish in Couffo River by the pesticides. The levels of most of the pesticides in fish are generally lowered. However the concentration of pesticides in fish shows the intensity of pollution from these four pesticides sources. Therefore, an increased of the concentration in these pesticides in Couffo water will obviously contribute to increase their concentration in fish present in the Couffo. Thanks to the results of the analysis of molecules involved in the work, doing without pesticides while guaranteeing a certain productivity seems not to be a utopia and therefore must not justify that these substances are also actively used.

\section{ACKNOWLEDGMENT}

We would like to say special thanks to IRGIB-AFRICA, Mrs Christophe S. HOUSSOU and Patrick A. EDORH for they contributions and valuable suggestions.

\section{REFERENCES}

Akomagni LA. 2006. Monographie de la commune de Djidja. Programme D'Appui au Démarrage des Communes, Afrique Conseil, $44 \mathrm{p}$
Akoto O, Andoh H, Darko G, Eshun K, Osei-Fosu P. 2013. Health risk assessment of pesticides residues in maize and cowpea from Ejura, Ghana. Chemosphere, 92: 67-73. Doi:10.1016/j. chemosphere. 02.057

Ayas Z, Ekmekci G, Ozmen M, Yerli SV. 2007. Histopathological changes in the livers and kidneys of fish in Sariyer Reservoir. Turkey Environmental Toxicology and Pharmacology, 23 (2): 242-249.

Carter AD, Heather AIJ. 1995. Pesticides in ground water: In: Best GA, Ruthven AD (eds.) Pesticides developments, impacts and controls. The Royale Society of chemistry, London, UK : 113-123 FDA (Food and Drug Administration). 2001. Environmental Chemical Contaminants and Pesticides. Ch. 9. In Fish and Fishery Products Hazards and Controls Guidance. 3rd ed, Center for Food and Applied Nutrition, Office of Seafood, Washington, DC.

Codex Alimentarius. 2014. Guidelines for the simple evaluation of Dietary exposure to food additive, FAO/WHO, 12 p

Fofana F, Labinter C, Mama D, Kaki C, Afouda A, Linsoussi C. 2014. Eco- Toxicological Approach as a Contribution to Integrated Water Management on Okpara Dame at Kpassa in Benin: Evaluation of contamination of fish and surface water by organochlorine Pesticides. Journal of water Ressource and Protection, 6 (14), 7 p

Hargrave BT, Harding GC, Vass WP, Erickson PE, Fowler BR, Scott V. 1992. Organochlorine Pesticides and Polychlorinated biphenyls in the Arctic Ocean food web-Archives of Envi. Contamination and Toxicology, 22: $41-54$

Harsimran KG, Harsh G. 2014. Pesticides: Environmental Impacts and Management Strategies, $44 \mathrm{p}$ Ibrahim L, Preuss TG, Ratte HT, Homman U. 2013. A list of fish species that are potentially exposed to pesticides in edge-of-field water bodies in the European Union a first step towards identifying vulnerable representatives for risk assessment. Environmental Science and Pollution Reasearch, 20 : 2679-2687

Kelly DW, Poulin R, Tompkins DM, Townsend C. 2010. Synergistic effets of glyphosate formulations and parasite infection on fish malformations and survival.Journal ofApplied Ecology, 47: 498-504

Köck-Schulmeyer M, Ginebreda A, Gonzalez S, Cortina JL, de Alda ML, Barcelo D. 2012. Analysis of the occurrence and risk assessment of polar pesticides in the Llobregat River Basin (NE Spain), Chemosphere, 86: 816

Konar SK. 2011. Pesticides and aquatic environment. Indian Journal of Fisheries: 80-85 
Larson SJ, Capel PD, Majewski M. 2010. Pesticides in surface waters: Distribution, trends, and governing factors

(3). CPC Press.

MAEP (Ministère de l'Agriculture, de l'Elevage et de la Pêche). 2008. Plan Stratégique de Relance du Secteur Agricole au Bénin. Orientations Stratégiques et Plan d'action, Cotonou, Bénin, $70 \mathrm{p}$

Pazou E, Glin LC, Vodouhè DS, Fanou J, Babadankpodji AP, Dassou S, Vodouhè $S$, van Hattum B, Swart K, van Gestel CAM. 2014. Pesticide contamination of the Dridji cotton plantation area in the Republic of Benin. African Journal of Food, Agriculture, Nutrition and Development, 14 (3): 8885-8902

Pereira L, Fernandes MN, Martinez CB. 2013. Hematological and biochemical alterations in the fish Prochilodus lineatus caused by the herbicide clomazone. Environmental Toxicology and Pharmacology, 36: 1- 8

Rosell G, Quero C, Coll J, Guerrero A. 2008. Bionational insecticides in pest management. Journal of Pesticide Science, 33: 103-121

SDS (Schéma de Développement Sectoriel). 2004. Document de synthèse, Diagnostic, Vision et Planification des projets sur 2004-2008 du secteur de l'agriculture, de l'élevage et de l'exploitation des ressources naturelles dans la commune de Djidja, PADeCOM/Zou, $159 \mathrm{p}$

Scholz NL, Fleishman E, Brown L, Werner I, Johnson ML, Brooks ML, Michaelmore CL, Schelenk DA. 2012. Perspective on modern pesticides, pelagic fish declines, and unknown ecological resilience in highly managed ecosystems. Bio. Science, 62: 428 - 434

Singh B, Mandal K. 2013. Environmental impact of pesticides belonging to newer chemistry. In: Dhawan, A.K., Singh, B., Brar-Bhullar, M., Arora, R. (ed.) Integrated Pesticide management. Scientific Publishers, Jodhpur, India: 152-190

WHO (World Health Organization). 1997. Guidelines for predicting dietary intake of pesticides residues (revised). Prepared by the Global Environment Monitoring System. Food Contamination Monitoring and Assessment (GEMS/Food) in collaboration with the Codex Program. 